\title{
Objective Response by mRECIST Is an Independent Prognostic Factor of Overall Survival in Systemic Therapy for Hepatocellular Carcinoma
}

\author{
Masatoshi Kudo
}

Department of Gastroenterology and Hepatology, Kindai University Faculty of Medicine, Osaka-Sayama, Japan

Prof. M. Kudo

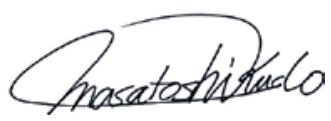

Editor Liver Cancer

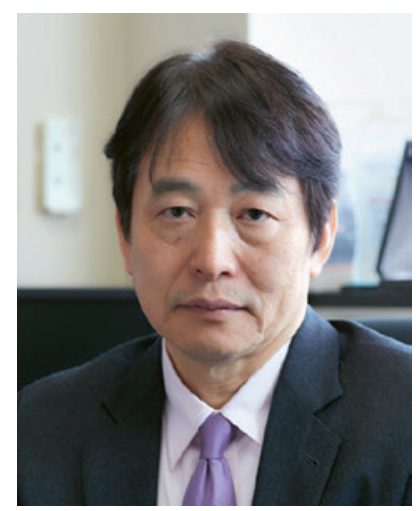

\section{Introduction}

The success of the REFLECT trial [1] has ended a "dark age" in drug development for firstline hepatocellular carcinoma (HCC) treatments; this "dark age" lasted 10 years following the approval of sorafenib in 2007. Currently, all of ongoing phase III clinical trials are immunotherapies, therefore the REFLECT study may be the first and last successful study of a molecular targeted agent (MTA) monotherapy other than sorafenib. Japan approved an additional indication of lenvatinib for HCC 5 months before any other country. This indication was approved in Japan on March 23, 2018, and then in the United States on August 15, 2018, in Europe on August 20, 2018, in South Korea on August 29, 2018, in China on September 4, 2018 , and in Taiwan on November 28,2018. This additional indication has now been approved in most countries around the world.

In Japan, more than 9,000 HCC patients have been treated with lenvatinib in the 12 months since its approval in last March. Similar to the REFLECT trial, the objective response rate of lenvatinib is reportedly as high as $40-50 \%$ in the real-world practice. In this editorial, recent evidence of the objective response by mRECIST as a prognostic factor of overall survival will be discussed. 
Table 1. Objective response by mRECIST predicts OS: retrospective analysis

\begin{tabular}{|c|c|c|c|c|c|c|}
\hline \multirow{2}{*}{$\begin{array}{l}\text { First author [ref.], } \\
\text { year }\end{array}$} & \multirow{2}{*}{$\begin{array}{l}\text { Agents (study } \\
\text { design) }\end{array}$} & \multirow{2}{*}{$\begin{array}{l}\text { ORR (mRECIST), } \\
\%(n / \text { total } n)\end{array}$} & \multicolumn{2}{|c|}{ Median OS, months } & \multirow{2}{*}{$\begin{array}{l}\text { HR } \\
(95 \% \mathrm{CI})\end{array}$} & \multirow[t]{2}{*}{$p$ value } \\
\hline & & & $\begin{array}{l}\text { responder } \\
(\mathrm{CR}+\mathrm{PR})\end{array}$ & $\begin{array}{l}\text { nonresponder } \\
(\mathrm{SD}+\mathrm{PD})\end{array}$ & & \\
\hline Ronot [2], 2014 & $\begin{array}{l}\text { sorafenib } \\
\text { (retrospective) }\end{array}$ & $28.1(18 / 64)$ & 25.5 & $\begin{array}{l}13.3(\mathrm{SD}) \\
5.7(\mathrm{PD})\end{array}$ & N/A & $<0.001$ \\
\hline Arizumi [3], 2014 & $\begin{array}{l}\text { sorafenib } \\
\text { (retrospective) }\end{array}$ & $22.8(36 / 158)$ & 25.4 & $\begin{array}{l}7.3(\mathrm{PD}) \\
5.7 \text { (short SD) }\end{array}$ & N/A & $<0.0001$ \\
\hline Edeline [4], 2012 & $\begin{array}{l}\text { sorafenib } \\
\text { (retrospective) }\end{array}$ & $22.6(12 / 53)$ & 18 & 8 & $\mathrm{~N} / \mathrm{A}$ & 0.013 \\
\hline Takada [5], 2015 & $\begin{array}{l}\text { sorafenib } \\
\text { (retrospective) }\end{array}$ & $13.1(25 / 191)$ & 22.0 & 10.0 & $\mathrm{~N} / \mathrm{A}$ & 0.0117 \\
\hline
\end{tabular}

OS, overall survival; ORR, objective response rate; CR, complete response; PR, partial response; SD, stable disease; PD, progressive disease; HR, hazard ratio; $\mathrm{CI}$, confidence interval; N/A, not available.

\section{Association between Objective Response and Overall Survival following MTA Treatment: Data from Retrospective Studies}

Ronot et al. [2] found a median survival of 25.5 months in 18/64 sorafenib-treated patients judged to be responders based on modified Response Evaluation Criteria in Solid Tumors (mRECIST); this represented a significant prolongation relative to that in nonresponders: 13.3 months in 29 patients with stable disease and 5.7 months in 17 patients with progressive disease $(p<0.001)$. In a retrospective study of 158 sorafenib-treated patients, Arizumi et al. [3] compared the 36 patients with complete or partial response with the nonresponders and found significantly better survival for responders than nonresponders (25.4 vs. 7.3 months). Edeline et al. [4] reported a response rate of $22.6 \%(12 / 53$ cases) in patients receiving sorafenib for unresectable HCC, with a median survival of 18 months for these responders, which was significantly superior to the median survival of 8 months in the 41 nonresponders $(p=0.013)$. In a similar retrospective study in 191 sorafenib-treated patients, Takada et al. [5] reported a response rate of $13.1 \%$ (25 patients) by mRECIST and significantly prolonged survival in the 25 responders relative to that in nonresponders (22 vs. 10 months; $p=0.0117)$. These studies are summarized in Table 1 . However, they were retrospective studies and, thus, do not represent a high level of evidence.

\section{Association between Objective Response and Overall Survival following MTA Treatment: Data from Randomized Controlled Trials}

Results from retrospective studies have been described above, but what about the picture in recent prospective studies? Table 2 presents a summary.

In one of these studies, Lencioni et al. [6] used data from a phase III comparative study of second-line treatment with brivanib to analyze responders using mRECIST. They found a response (mRECIST) in 11.5\% (26/226) of patients receiving brivanib, and these responders to brivanib therapy clearly survived significantly longer than nonresponders (15.0 vs. 9.4 months; hazard ratio [HR] $0.31 ; 95 \%$ CI $0.16-0.60 ; p<0.001$ ) by landmark analysis at 15 months. Multivariate analysis with time-dependent covariates also clearly demonstrated that 
Table 2. Objective response by mRECIST predicts OS: results of RCTs

\begin{tabular}{|c|c|c|c|c|c|c|}
\hline \multirow{2}{*}{$\begin{array}{l}\text { First author [ref.], } \\
\text { year }\end{array}$} & \multirow{2}{*}{$\begin{array}{l}\text { Agents (study } \\
\text { design) }\end{array}$} & \multirow{2}{*}{$\begin{array}{l}\text { ORR (mRECIST), } \\
\%(n / \text { total } n)\end{array}$} & \multicolumn{2}{|c|}{ Median OS, months } & \multirow[t]{2}{*}{ HR $(95 \%$ CI) } & \multirow[t]{2}{*}{$p$ value } \\
\hline & & & $\begin{array}{l}\text { responder } \\
(\mathrm{CR}+\mathrm{PR})\end{array}$ & $\begin{array}{l}\text { nonresponder } \\
(\mathrm{SD}+\mathrm{PD})\end{array}$ & & \\
\hline Lencioni [6], 2017 & $\begin{array}{l}\text { brivanib } \\
\text { (phase } 3 \text { RCT) }\end{array}$ & $11.5(26 / 226)$ & 14.3 & 9.4 & $\begin{array}{l}0.31 \\
(0.16-0.60)\end{array}$ & $<0.001$ \\
\hline Meyer [7], 2017 & $\begin{array}{l}\text { nintedanib + } \\
\text { sorafenib } \\
\text { (phase } 2 \text { RCT) }\end{array}$ & $15.6(28 / 180)$ & 16.7 & 10.9 & $\begin{array}{l}0.544 \\
(0.335-0.881)\end{array}$ & 0.0122 \\
\hline Kudo [8], 2018 & $\begin{array}{l}\text { sorafenib } \\
\text { (phase } 3 \text { RCT) }\end{array}$ & $18.8(18 / 96)$ & 27.2 & 8.9 & $\mathrm{~N} / \mathrm{A}$ & $<0.001$ \\
\hline
\end{tabular}

OS, overall survival; RCT, randomized controlled trial; ORR, objective response rate; CR, complete response; PR, partial response; $\mathrm{SD}$, stable disease; $\mathrm{PD}$, progressive disease; $\mathrm{HR}$, hazard ratio; $\mathrm{CI}$, confidence interval; N/A, not available.

objective response based on mRECIST was an independent prognostic factor. In the discussion section of their report, Lencioni et al. [6] state that the level of evidence of this study is high due to the phase III randomized controlled nature of the original study.

Meyer et al. [7] investigated RECIST 1.0 and mRECIST responses based on a clinical study for comparison of nintedanib $200 \mathrm{mg}$ b.i.d. versus sorafenib $400 \mathrm{mg}$ b.i.d. (the data were pooled from 2 independently performed phase I/II open-label, multi-center clinical studies in Europe and Asia; the phase I portions were excluded and phase II patients had been randomized to the 2 respective arms in a 2:1 ratio). The mRECIST evaluation revealed 28 responders and 152 nonresponders from a total of 180 patients, with a median overall survival of 16.7 months in the 28 responders and 10.9 months in the nonresponders; survival was significantly superior in responders (HR 0.544; 95\% CI 0.335-0.881; $p=0.0122$ ). Multivariate analysis of overall survival in the study by Meyer at al. [7] (similar to that performed by Lencioni et al. [6]) revealed mRECIST response as an independent prognostic factor (HR $0.62 ; 95 \%$ CI $0.38-1.01 ; p=0.053$ ). These results were similar to those obtained by Lencioni et al. [6], although the difference was not significant.

Kudo et al. [8] investigated sorafenib in a prospective, phase III comparative study, the SILIUS study. They noted a response by mRECIST in 18/96 patients receiving sorafenib monotherapy (response rate of 18.8\%). Responders survived for significantly longer than nonresponders ( 27.2 vs. 8.9 months; $p<0.001$ ).

The responder analyses in the above 3 studies were based on data from prospective clinical studies, and the analysis results can be described as representing very strong evidence. With the high level of evidence provided by data from randomized controlled trials, these 3 prospective clinical studies have demonstrated that where MTAs elicit a response per mRECIST, responders experience prolonged survival. These studies have also clearly demonstrated an increase in the patient population that can derive a survival benefit from drugs that elicit a high response rate - the proportion of patients with a response. This suggests that a greater number of HCC patients will have the advantage of prolonged survival commensurate with the high response rate for drugs such as lenvatinib.

The 2018 updated EASL clinical practice guidelines on HCC state that response by mRECIST is an independent prognostic factor for survival with locoregional therapy based on the meta-analysis study [9]. Similarly, they clearly state that response determined by mRECIST for systemic therapy is an independent prognostic factor. However, it is noted that further studies are warranted to confirm this evidence [10]. 
Kudo: Objective Response by mRECIST Is an Independent Prognostic Factor of Overall Survival in Systemic Therapy for Hepatocellular Carcinoma

Table 3. Landmark analyses for OS by objective response in the overall REFLECT population

\begin{tabular}{|c|c|c|c|c|c|c|c|}
\hline \multirow{2}{*}{$\begin{array}{l}\text { First } \\
\text { author [ref.], } \\
\text { year }\end{array}$} & \multirow{2}{*}{$\begin{array}{l}\text { Agents } \\
\text { (study design) }\end{array}$} & \multirow{2}{*}{$\begin{array}{l}\text { ORR (mRECIST), } \\
\%(95 \% \mathrm{CI}) \\
(n / \text { total } n)\end{array}$} & \multicolumn{2}{|c|}{ Median OS, months (95\% CI) } & \multicolumn{3}{|c|}{ Landmark analyses, HR (95\% CI) } \\
\hline & & & $\begin{array}{l}\text { responder } \\
(\mathrm{CR}+\mathrm{PR})\end{array}$ & $\begin{array}{l}\text { non- } \\
\text { responder } \\
(\mathrm{SD}+\mathrm{PD})\end{array}$ & 2 months & 4 months & 6 months \\
\hline $\begin{array}{l}\text { Kudo [11], } \\
2019\end{array}$ & $\begin{array}{l}\text { lenvatinib + } \\
\text { sorafenib } \\
\text { (phase } 3 \text { RCT) }\end{array}$ & $\begin{array}{l}16.7(14.3-19.0) \\
(159 / 954)\end{array}$ & $\begin{array}{l}22.4 \\
(19.7-26.0)\end{array}$ & $\begin{array}{l}11.4 \\
(10.3-12.3)\end{array}$ & $\begin{array}{l}0.75 \\
(0.57-0.98)\end{array}$ & $\begin{array}{l}0.72 \\
(0.56-0.92)\end{array}$ & $\begin{array}{l}0.73 \\
(0.57-0.93)\end{array}$ \\
\hline
\end{tabular}

OS, overall survival; RCT, randomized controlled trial; ORR, objective response rate; CR, complete response; PR, partial response; SD, stable disease; $\mathrm{PD}$, progressive disease; HR, hazard ratio; CI, confidence interval.

Table 4. Multivariate Cox regression analyses for predictors of survival with objective response as a timedependent covariate in the REFLECT trial

\begin{tabular}{llr}
\hline Parameter & \multicolumn{2}{l}{ Multivariate analysis } \\
\cline { 2 - 3 } & HR $(95 \% \mathrm{CI})$ & $p$ value \\
\hline Macroscopic portal vein invasion (yes vs. no) & $1.366(1.141-1.636)$ & 0.0007 \\
Baseline AFP (ng/mL) (<200 vs. $\geq 200)$ & $0.564(0.483-0.659)$ & $<0.0001$ \\
No. of tumor sites at baseline (2 vs. 1) & $1.400(1.180-1.662)$ & $<0.0001$ \\
No. of tumor sites at baseline ( $\geq 3$ vs. 1) & $2.024(1.659-2.469)$ & $<0.0001$ \\
Involved tumor in liver (yes vs. no) & $1.675(1.203-2.332)$ & 0.0022 \\
Etiology HBV (yes vs. no) & $1.199(1.031-1.395)$ & 0.0185 \\
Prior procedure for HCC (yes vs. no) & $0.844(0.723-0.986)$ & 0.0323 \\
Treatment (LEN vs. SOR) & $0.855(0.734-0.996)$ & 0.0439 \\
Objective response (yes vs. no) & $0.611(0.490-0.762)$ & $<0.0001$ \\
\hline
\end{tabular}

Cited from Kudo et al. [11]. HR, hazard ratio; CI, confidence interval; AFP, $\alpha$-fetoprotein; HBV, hepatitis B virus; HCC, hepatocellular carcinoma; LEN, lenvatinib; SOR, sorafenib.

\section{Association between Objective Response and Overall Survival in the REFLECT Trial}

The results of responder analysis in the patient population of the REFLECT trial were presented at the ASCO-GI symposium in January 2018 [11]. The responder analysis targeted the total patient population of 954 enrolled in the REFLECT study (478 in the lenvatinib arm and 476 in the sorafenib arm) and revealed 159 responders (response rate 16.7\%) and 795 nonresponders. Kaplan-Meier analysis revealed clearly superior overall survival in responders relative to nonresponders, at 22.4 months (95\% CI 19.7-26.0) in responders versus 11.4 months in nonresponders (95\% CI 10.3-12.3). Landmark analysis, performed to eliminate lead-time bias or guarantee time bias, revealed HRs of 0.75 (95\% CI 0.57-0.98), 0.72 (95\% CI 0.56-0.92), and 0.73 (95\% CI 0.57-0.93) at the respective 2-, 4-, and 6-month time points, consistently demonstrating longer survival in responders than in nonresponders (Table 3 ). Multivariate analysis with time-dependent covariates also revealed that response was an independent prognostic factor (HR 0.611; 95\% CI 0.490-0.762; $p<0.0001$ ). Other prognostic factors identified were treatment (lenvatinib), macroscopic portal vein thrombus (absence), baseline $\alpha$-fetoprotein level $(<200 \mathrm{ng} / \mathrm{mL}$ ), tumor site ( 1 organ), presence or absence of intrahepatic lesions (absence), type of hepatitis (not hepatitis B), and pretreatment (performed) (Table 4). Surprisingly, lenvatinib treatment was demonstrated to be a significantly superior 
prognostic factor to sorafenib treatment, and, at the same time, prolonged survival was determined for responders, irrespective of whether they were receiving lenvatinib or sorafenib. The results produced with data from the above-mentioned previously conducted results from 3 randomized controlled trials were consistent and further demonstrated that response measured by mRECIST is an independent prognostic factor in an individual patient who is treated with systemic therapy.

\section{Conclusion}

Response by mRECIST has been demonstrated as an independent prognostic factor for HCC patients on systemic therapy from a broad range of data. Accordingly, drugs that elicit high response rates can be expected to prolong overall survival in a large number of patients.

\section{Disclosure Statement}

Masatoshi Kudo received lecture fees from Bayer, Eisai, MSD, and Ajinomoto, research grants from Chugai, Otsuka, Takeda, Taiho, Sumitomo Dainippon, Daiichi Sankyo, MSD, Eisai, Bayer, AbbVie, Medico's Hirata, Astellas Pharma, and Bristol-Myers Squibb, and advisory consulting fees from Kowa, MSD, BristolMyers Squibb, Bayer, Chugai, Taiho, Eisai, and Ono Pharmaceutical.

\section{References}

1 Kudo M, Finn RS, Qin S, Han KH, Ikeda K, Piscaglia F, et al. Lenvatinib versus sorafenib in first-line treatment of patients with unresectable hepatocellular carcinoma: a randomised phase 3 non-inferiority trial. Lancet. 2018 Mar;391(10126):1163-73.

2 Ronot M, Bouattour M, Wassermann J, Bruno O, Dreyer C, Larroque B, et al. Alternative Response Criteria (Choi, European association for the study of the liver, and modified Response Evaluation Criteria in Solid Tumors [RECIST]) versus RECIST 1.1 in patients with advanced hepatocellular carcinoma treated with sorafenib. Oncologist. 2014 Apr;19(4):394-402.

3 Arizumi T, Ueshima K, Chishina H, Kono M, Takita M, Kitai S, et al. Duration of stable disease is associated with overall survival in patients with advanced hepatocellular carcinoma treated with sorafenib. Dig Dis. 2014; 32(6):705-10.

4 Edeline J, Boucher E, Rolland Y, Vauléon E, Pracht M, Perrin C, et al. Comparison of tumor response by Response Evaluation Criteria in Solid Tumors (RECIST) and modified RECIST in patients treated with sorafenib for hepatocellular carcinoma. Cancer. 2012 Jan;118(1):147-56.

5 Takada J, Hidaka H, Nakazawa T, Kondo M, Numata K, Tanaka K, et al. Modified response evaluation criteria in solid tumors is superior to response evaluation criteria in solid tumors for assessment of responses to sorafenib in patients with advanced hepatocellular carcinoma. BMC Res Notes. 2015 0ct;8(1):609.

6 Lencioni R, Montal R, Torres F, Park JW, Decaens T, Raoul JL, et al. Objective response by mRECIST as a predictor and potential surrogate end-point of overall survival in advanced HCC. J Hepatol. 2017 Jun;66(6): 1166-72.

7 Meyer T, Palmer DH, Cheng AL, Hocke J, Loembé AB, Yen CJ. mRECIST to predict survival in advanced hepatocellular carcinoma: analysis of two randomised phase II trials comparing nintedanib vs sorafenib. Liver Int. 2017 Jul;37(7):1047-55.

8 Kudo M, Ueshima K, Yokosuka O, Ogasawara S, Obi S, Izumi N, et al.; SILIUS study group. Sorafenib plus low-dose cisplatin and fluorouracil hepatic arterial infusion chemotherapy versus sorafenib alone in patients with advanced hepatocellular carcinoma (SILIUS): a randomised, open label, phase 3 trial. Lancet Gastroenterol Hepatol. 2018 Jun;3(6):424-32.

9 Vincenzi B, Di Maio M, Silletta M, D’Onofrio L, Spoto C, Piccirillo MC, et al. Prognostic Relevance of Objective Response According to EASL Criteria and mRECIST Criteria in Hepatocellular Carcinoma Patients Treated with Loco-Regional Therapies: A Literature-Based Meta-Analysis. PLoS One. 2015 Jul;10(7):e0133488.

10 European Association for the Study of the Liver. EASL Clinical Practice Guidelines: Management of hepatocellular carcinoma. J Hepatol. 2018 Jul;69(1):182-236.

11 Kudo M, Finn RS, Qin S, Han KH, Ikeda K, Cheng AL, et al. Analysis of survival and objective response (OR) in patients with hepatocellular carcinoma in a phase III study of lenvatinib (REFLECT). J Clin Oncol. 2019 Feb; 37(4 suppl):abstract 186. 